Discussion/conclusion These results suggest that we need to review our current testing policy.

\section{P182 HIV FILM CLUB: AN INNOVATIVE METHOD FOR HIV MEDICAL EDUCATION IS ACCEPTABLE AND EFFECTIVE}

${ }^{1}$ Sarah Cavilla*, 'Duncan Churchill, ${ }^{1,2}$ Daniel Richardson. ${ }^{1}$ Brighton \& Sussex University NHS Trust; ${ }^{2}$ Brighton \& Sussex Medical School

\subsection{6/sextrans-2016-052718.232}

Background/introduction Training and continuing professional development in HIV medicine requires knowledge of the history of HIV. Locally we have instigated an HIV film club. There is no literature on the impact of HIV medical education using film. To date, we have had 2 educational events using "How to Survive a Plague" [Producer: D.France, 2013] and "We were Here", [Producers: D. Weissman \& B.Weberdate, 2011].

Methods An anonymous electronic survey was sent to 13 participants exploring what they had learnt, influence on practice and their opinion on the importance of the history for trainees.

Results 10/13 completed the survey. 10/10 (100\%) had learnt something new: appreciating HIV stigma in greater depth, recognition of the role of HIV negative MSM support and the importance in mechanisms for licensing new HIV drugs. 4/10 (40\%) reported a change in practice such as a greater awareness of the psychological impact on long term survivors. 3/10 (30\%) said that the films had underpinned and increased their understanding of the importance of Pre- exposure Prophylaxis (PrEP) and Direct Acting Antivirals provision in hepatitis $\mathrm{C}$ for patients currently. $10 / 10(100 \%)$ felt it was important to have an comprehension of the history and stigma of HIV. Additional film recommendations included: "And the Band Played On" [Spelling, 1994], "Philadelphia" [J.Demme, 1993] and "Angels in America" [C.Costas, 2003].

Discussion/conclusion Innovation and progress in HIV medical education requires exploring new models of teaching: using the medium of film is ideal for HIV medicine where the field has transformed beyond recognition. Film nights were useful and interesting.

\section{P183 MULTICENTRE AUDIT ON THE DIAGNOSIS AND MANAGEMENT OF TRICHOMONAS VAGINALIS}

\begin{abstract}
${ }^{1}$ Martin Lechelt* ${ }^{1}$ Richard Shen, ${ }^{3}$ Huw Price, ${ }^{2}$ Sabri AbuBakar, ${ }^{2}$ Henna Jaleel, ${ }^{4}$ Malaki Ramogi, ${ }^{5}$ Gail Crowe. 'Norh East London Foundation Trust, Essex, UK; ${ }^{2}$ Southend University Hospital Foundation Trust, Essex, UK; ${ }^{3}$ Mid Essex Hospital NHS Trust, Essex, UK; ${ }^{4}$ Colchester Hospital NHS Trust, Essex, UK; ${ }^{5}$ Princess Alexandra Hospital NHS Trust, Essex, UK
\end{abstract}

\subsection{6/sextrans-2016-052718.233}

Background/introduction Trichomonas vaginalis (TV) is a sexually transmitted parasitic infection. It is commonly found in patients of non-white ethnicity and in females is usually symptomatic though may be asymptomatic in up to $50 \%$. Untreated infection can lead to complications such as pelvic inflammatory disease, preterm delivery and increased risk of transmission of HIV.

Aim(s)/objectives To compare the management of TV in five GUM clinics across Essex to the BASHH 2014 TV guidelines

Methods Audit of 30 case notes of patients diagnosed with TV (SHHAPT code C6A) between January and December 2014
Results

\begin{tabular}{ll} 
Abstract P183 Table 1 & Audit of Trichomonas Vaginalis in Essex \\
\hline Total Number of patients & $146(100 \%)$ \\
Age - median (range) & $27(15-57)$ years \\
Sex - females & $98 \%$ \\
Ethnicity - White British & $79 \%$ \\
Black African & $5 \%$ \\
others & $16 \%$ \\
Diagnosis - Wet mount (range) & $57(27-87) \%$ \\
Culture (range) & $57.1(38-71) \%$ \\
HVS & $78 \%$ \\
Symptomatic & $71 \%$ \\
Asymptomatic & $12 \%$ \\
Cervical smear TV + & $17 \%$ \\
Contact CT/GC & $17 \%$ \\
BASHH Auditable outcomes & $99 \%$ \\
- 1 & st line treatment \\
- Written information given & $74 \%$ \\
- PN carried out & $95 \%$ \\
\hline
\end{tabular}

Discussion/conclusion In Essex 79\% of patients diagnosed with TV were of white British ethnicity, reflecting local demographics. Nearly all were female and the majority were symptomatic. All clinics performed wet mount to diagnosed TV. It is cheap and gives an immediate result but the sensitivity is skill dependent. The regional audit group felt PCR testing should be used in the future. Written information on TV should also be improved by using approved websites and patients given BASHH leaflets.

\section{P184 WHAT'S IN A NAME? ESTABLISHING BRAND VALUES FOR A NEW SEXUAL HEALTH SERVICE}

Joelle Turner*, Bernie Rigoulay, Tom Joyce. Luton \& Dunstable University Hospital NHS Foundation Trust, Luton, UK

\subsection{6/sextrans-2016-052718.234}

Background/introduction Award of a new contract for an integrated sexual health service requires a fresh brand identity for service launch.

Aim(s)/objectives To establish from service users and stakeholders the important brand values for a sexual health service.

Methods An online survey was designed to investigate public opinion about naming and brand values. This was distributed via email to all hospital and local council employees and through local stakeholder and youth networks.

Results In February 2016, 103 online surveys were completed by service users and 256 by potential service users. Of 359 respondents, $56 \%$ were young people $(<25)$, 76\% were female, $86 \%$ identified as heterosexual and $50 \%$ were White British. The most important values for a sexual service were confidentiality (27\%), professional and knowledgeable staff (16\%) and friendly and approachable staff (14\%). The most common reasons for difficulty using a sexual health service were embarrassment (50\%), unsuitable opening hours (40\%) and not knowing where to find services (25\%). Regarding staff uniforms, 58\% of respondents preferred 'uniform but not too formal', $37 \%$ preferred 'formal wear (traditional uniform)' and 5\% 'something else'. 'A name that clearly states what the service is' was preferred overall, though differences were marginal (see Table 1). 